\title{
SCIDOC
}

\author{
International Journal of Dentistry and Oral Science (IJDOS) \\ ISSN: 2377-8075
}

\section{Association between The Degree Of Tooth Mobility And The Type Of Furcation Defects Among Chronic Periodontitis Patients - A Retrospective Analysis}

Research Article

R. Saravanan ${ }^{1}$, Priya Lochana Gajendran $2^{*}$, Balaji Ganesh $S^{3}$

${ }^{1}$ Department of Periodontics, Saveetha Dental College and Hospitals, Saveetha Institute of Medical and Technical Sciences, Saveetha University, Chennai, India.

${ }^{2}$ Senior Lecturer, Department of Periodontics, Saveetha Dental College and Hospitals, Saveetha Institute of Medical and Technical Sciences, Saveetha University, Chennai, 600077, India.

${ }^{3}$ Senior Lecturer, Department of Periodontics, Saveetha Dental College and Hospitals, Saveetha Institute of Medical and Technical Sciences, Saveetha University, Chennai, 600077, India.

\section{Abstract}

\begin{abstract}
A multitude of factors are likely to influence the treatment decision for the periodontally involved molar. The most important ones are furcation and mobility with respect to the posterior teeth. The aim of the study is to retrospectively assess the association between the degree of tooth mobility and the type of furcation defects among chronic periodontitis patients. A total of 333 patients who had chronic periodontitis were included in the study. Demographic details such as patient identity number (PID. No), age and sex were recorded. Degree of mobility and grades of furcation involvement for all the patients were recorded. The required data was collected and analysed using SPSS(Statistical Package For The Social Sciences) Software. Chi-square test was used to study association between the parameters. The results were considered to be of statistical significance if $\mathrm{p}<0.05$. From 333 patients, a total of 1202 teeth were diagnosed with periodontal mobility out of which 940 were anteriors and 262 were posteriors. Among mobility of teeth, $76.40 \%$ of teeth had grade 1 mobility, $13.32 \%$ of teeth had grade 2 mobility and the remaining $10.28 \%$ of teeth had grade 3 mobility. A total of 330 teeth had furcation involvement.Based on the severity of involvement $13.03 \%$ of teeth had grade 1 furcation, $55.15 \%$ of teeth had grade 2 furcation, $22.12 \%$ had grade 3 furcation and grade 4 furcation was $9.70 \%$. among the grade 1 mobility teeth. There was a statistically significant association seen between the degree of Mobility and furcation involvement among the posterior teeth. There was a statistically significant association seen between the degree of Mobility and furcation involvement among the maxillary and mandibular posterior teeth. $(\mathrm{p}<0.05)$ Within the limitations of the present retrospective analysis, a significant association exists between degree of tooth mobility and the severity of furcation involvement. Thus tooth mobility may accelerate the progression of periodontal disease in teeth with furcation involvement sites where plaque control is compromised.
\end{abstract}

Keywords: Attachment Loss; Furcation; Mobility; Periodontitis; Prognosis.

\section{Introduction}

Periodontitis is a chronic inflammatory disease affecting the supporting structures of the teeth. The increase in the various pro-inflammatory cytokines levels have been attributed to the etiopathogenesis of the diseases [1,2]. The clinical features of periodontitis includes gingival inflammation, bleeding on probing, increasing probing pocket depth and clinical attachment loss. The presence of furcation involvement or interradicular bone loss is one common finding among periodontitis patients [3].

Anatomical variations present in the furcations such as furcation entrance width, root trunk length and the presence of root concavities, cervical enamel projections, bifurcation ridges, and enamel pearls can increase the severity of furcation involvement [4]. Higher morbidity and compromised prognosis for molars with furcation involvement have been reported in several retrospective studies of tooth loss [5]. Furcation involvement increases the risk for tooth loss and the frequency of furcation involvement

*Corresponding Author:

Priya Lochana Gajendran,

Senior Lecturer, Department of Periodontics, Saveetha Dental College and Hospitals, Saveetha Institute of Medical and Technical Sciences, Saveetha University, Chennai, 600077, India.

Tel: 9941413881

E-mail: priya.sdc@saveetha.com

Received: November 10, 2020

Accepted: December 15, 2020

Published: December 18, 2020

Citation: R. Saravanan, Priva Lochana Gajendran, Balaji Ganesh S. Association between The Degree Of Tooth Mobility And The Type Of Furcation Defects Among Chronic Periodontitis Patients - A Retrospective Analysis. Int J Dentistry Oral Sci. 2020;7(12):1236-1241. doi: http://dx.doi.org/10.19070/2377-8075-20000244

Copyright: Priya Lochana Gajendran ${ }^{\circ} 2020$. This is an open-access article distributed under the terms of the Creative Commons Attribution License, which permits unrestricted use, distribution and reproduction in any medium, provided the original author and source are credited. 
increases with age [6].

The prevalence of furcation involvement in the maxillary and mandibular molars ranges from $25 \%$ to $52 \%$ and from $16 \%$ to $35 \%$, respectively [7-9]. Tooth type and degree of furcation involvement were considered as the most important factors influencing the treatment protocol [10]. Longitudinal prospective [11] and retrospective $[12,13]$ studies showed that periodontal treatment shows better results in single-rooted teeth or non-furcated molars with respect to molars with furcation lesions.

Tooth mobility has been the subject of investigation by many clinicians, as its proper interpretation denotes the stability or instability of the periodontium over a period of time. Longitudinal clinical studies have concluded that mobile teeth with a furcation involvement are at a greater risk for attachment loss when compared to teeth without mobility $[8,14-15]$. The treatment of a multi-rooted tooth with a furcation involvement is still a challenge for clinicians. Therefore, diagnosis and its correct interpretation are essential when establishing an adequate treatment.

Previously our team had conducted various studies on treatment modalities for periodontal disease and periodontal procedures [1, 16-19], studies correlating various disease and factors related to periodontal disease [20, 21], in-vitro \& radiological studies [21-23] and reviews on various topics which gave a deeper understanding of the subject over the past five years [1,24-28]. The current study aims to find the association between the degree of tooth mobility and the type of furcation defects among periodontitis patients.

\section{Materials and Methods}

The retrospective cross sectional study was carried out by the analysis of the patients records who had visited the department of Periodontics of Saveetha dental college and Hospitals from June 2019-March 2020. The study design was reviewed and approved by the ethical committee of the institute. (ethical approval number SDC/SIHEC/2020/DIASDATA/0619-0320). A total of 4000 case records were analysed for the study. Data from 333 patients who were diagnosed with Chronic Peridontitis at the Department of Periodontics were included in this study.Casesheets with incomplete data were excluded from the study.

Demographic details such as patient identity number (PID.No), age and sex were recorded. Patients with Chronic Periodontitits were included in the study.Based on the severity of the periodontal disease the patients were categorised into those who had generalised chronic periodontitis and generalised chronic gingivitis with localised chronic periodontitis. Patients with Aggressive periodontitis,those with previous history of periodontal surgery, patients with smoking habits and presence of any other systemic disease were excluded from the study.

The degree of mobility (Miller,1985) from the case records of the patients was noted. Based on Miller classification of mobility, Grade 0-No mobility, Grade 1-<1mm(Horizontal) mobility,Grade $2>1 \mathrm{~mm}$ (Horizontal) mobility and Grade III$>1 \mathrm{~mm}$ (Horizontal+Vertical) mobility the data was collected.All the teeth with mobility were recorded and were divided into anterior and posterior teeth. The posterior teeth were categorised into three groups based on the degree of mobility into grade 1 , grade 2 and grade 3 . The grades of furcation involvement were recorded based on Glickman(1953) classification of furcation. Grade 1 furcation had Incipient Furcation, Grade 2 had a Cul de sac furcation involvement, in Grade 3 furcation inter radicular bone not attached to the dome of furcation,periodontal probe complete through the furaction seen as radiolucent area and Grade 4-Soft tissue apically receded tunnel, interdental bone destroyed, furcation is clinically visible.

\section{Statistical Analysis}

The data obtained analysed using statistical software SPSS version 23.0 (Statistical Package For The Social Sciences). Chi-square test was used to study association between the parameters. The results were considered to be of statistical significance if $p<0.05$.

\section{Results And Discussion}

A total of 333 patients with chronic periodontitis included in this retrospective analysis. Majority of the subjects (51.81\%) were in the age group of 35 to 55 years, whereas the remaining $34.94 \%$ of patients were in the age group of 56 to 65 years and only 13.25 $\%$ of the subjects were within the age group of 19 to 34 years. (Figure 1). Among the study population, $60.00 \%$ of them were males and $40.00 \%$ of them were females. (Figure 2). Based on the periodontal diagnosis, the majority $(88.5 \%)$ of the subjects had generalised chronic periodontitis and around (11.45) \% had localised chronic periodontitis (Figure 3).

Figure 1. This graph represents the percentage distribution of different age groups of the study subjects, where $\mathrm{X}$ axis denotes age and $\mathrm{Y}$ axis denotes number of patients. Majority of patients are in the age group of 35-55 years of age(Purple) $(51.81 \%)$ followed by $56-65$ years of age(Blue)(34.94\%) and $19-34$ years of age(Green)(13.25\%).

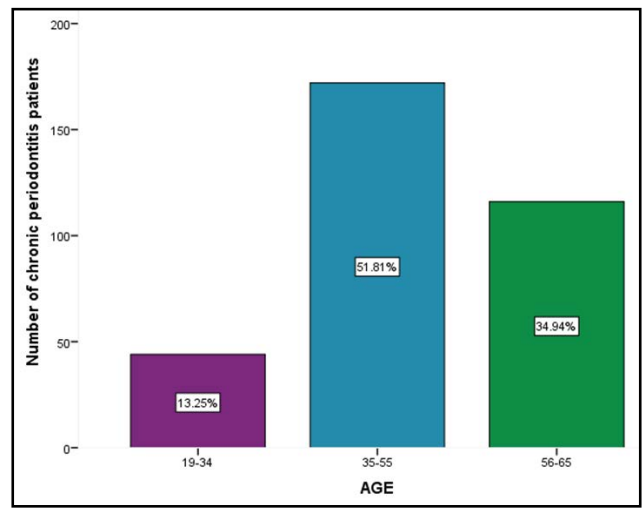


Figure 2. This graph represents the percentage of gender distribution among the study population, where $\mathbf{X}$ axis denotes Gender criteria and $\mathrm{Y}$ axis denotes number of patients.. There were more males (Dark blue) $(60.36 \%)$ than females(Orange) $(39.64 \%)$.

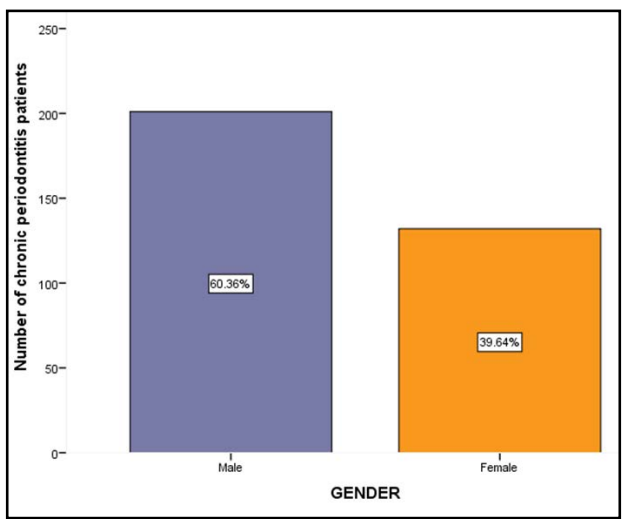

Figure 3. This graph represents Periodontal status of the study subjects, where $\mathbf{X}$ axis denotes Periodontal diagnosis and $\mathbf{Y}$ axis denotes number of patients. Generalised chronic Periodontitis(Yellow) $(\mathbf{8 8 . 5 5 \% )}$ was predominantly seen among the subjects with lesser percentage of Generalised chronic gingivitis with localised chronic Periodontitis(Lavender) (11.45\%).

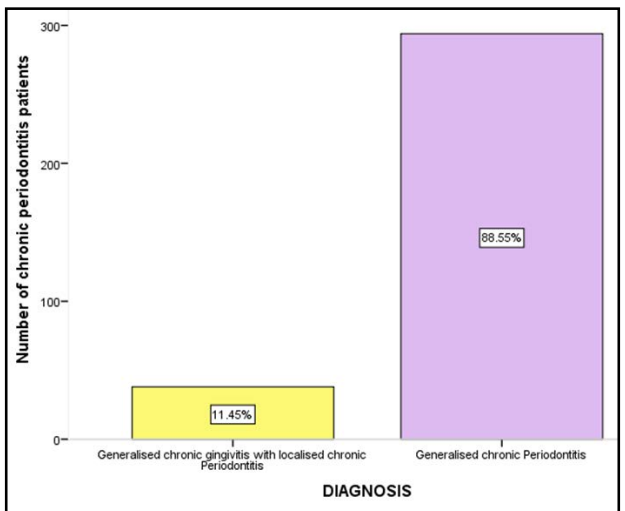

Figure 4. This graph represents the degree of mobility distribution among the study subjects, where $\mathrm{X}$ axis denotes degree of Mobility and $\mathrm{Y}$ axis denotes number of patients. Grade 1 mobility(Dark grey)(77.77\%) was seen predominantly seen among patients the subjects with lesser percentage of grade 2 mobility(Light green)(11.07\%) and grade 3 mobility(Light

Blue)(11.16\%).

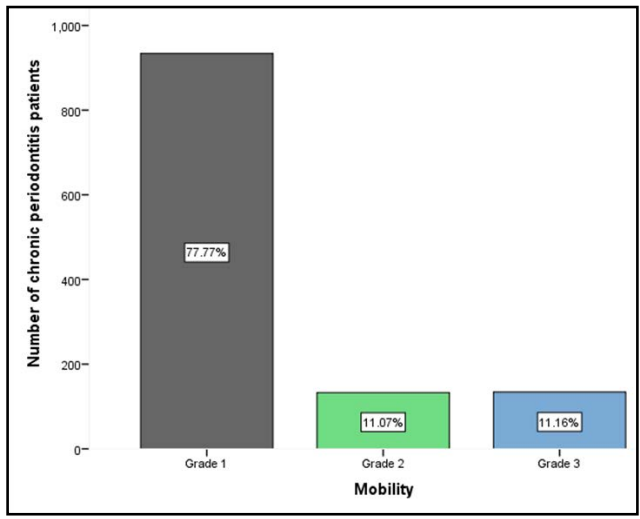

From 333 patients, a total of 1202 teeth were diagnosed with periodontal mobility out of which 940 were anteriors and 262 were posteriors.Among mobility of teeth, $77.77 \%$ of teeth had grade 1 mobility, $11.07 \%$ of teeth had grade 2 mobility and the remaining $11.16 \%$ of teeth had grade 3 mobility (Figure 4).

A total of 330 teeth were with furcation involvement.Based on the severity of involvement $13.03 \%$ of teeth had grade 1 furcation , $55.15 \%$ of teeth had grade 2 furcation, $22.12 \%$ had grade 3 furcation and grade 4 furcation was $9.70 \%$ (Figure 5).
There was an association between mobility in maxillary posterior and furcation in maxillary posteriors(p value 0.053) (Figure 6). There was an association between mobility in mandibular posteriors and furcation in mandibular posteriors ( $\mathrm{p}$ value-0.043) (Figure 7).

A multitude of factors are likely to influence the treatment decision for the periodontally involved molar. The most important ones are furcation and mobility with respect to the posterior teeth. Tooth mobility defined as the slight displacement of the clinical crown of a tooth, that is allowed by the resilience of an intact and healthy periodontium, under the application of a moderate force 
Figure 5. This graph represents degree of furcation involvement among the study subjects, where $\mathrm{X}$ axis denotes the degree of furcation involvement and $\mathrm{Y}$ axis denotes number of patients.From this figure we can infer that,grade 2 furcation(Blue) $(55.15 \%)$ was seen predominant among the subjects with a lesser percentage of grade 3 furcation(Green)(22.12\%), grade 1 furcation(Grey)(13.03\%) and grade 4 furcation(Yellow) $(9.70 \%)$.

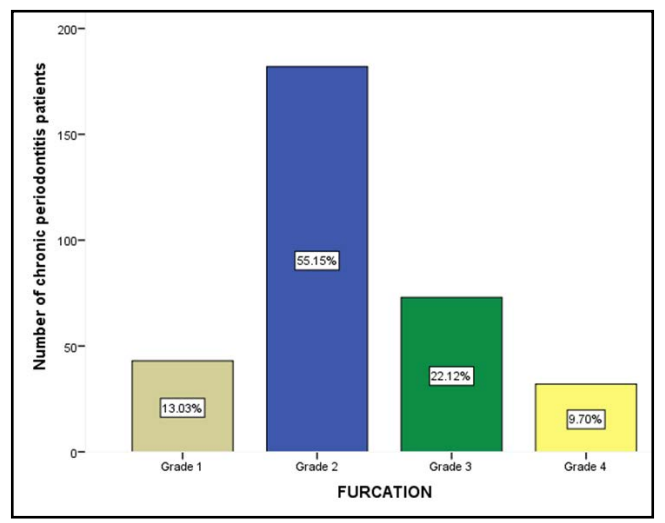

Figure 6. This bar graph represents the association between furcation and mobility in maxillary posteriors, where $\mathrm{X}$ axis denotes the degree of mobility in maxillary posteriors and $\mathrm{Y}$ axis denotes number of patients. There were more number of grade 2 and grade 3 furcation involvement in the grade 3 mobility teeth when compared with grade 2 and grade 1 mobile teeth among the maxillary posteriors. However when compared with the teeth with no mobility, the grade 2 furcation involved teeth were more in number than in the grade 3 mobility group. The association between the degree of Mobility and severity of furcation involvement was statistically significant $($ Chi square test done, $p$ value $=0.043(p<0.05)$.

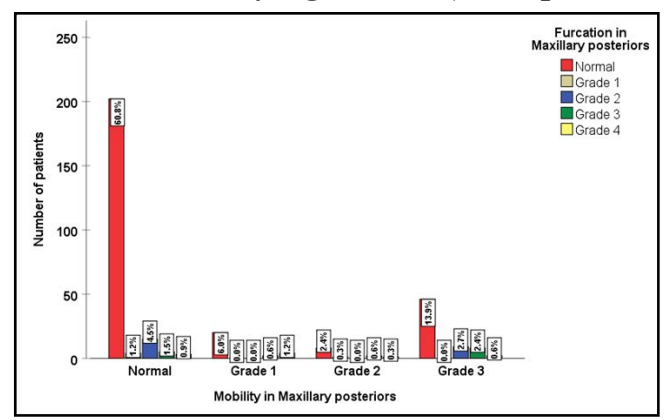

Figure 7. This bar graph represents the association between furcation and mobility in mandibular posteriors, where $\mathbf{X}$ axis denotes mobility in mandibular posteriors and $\mathrm{Y}$ axis denotes number of patients. There were more number of grade 3 and grade 4 furcation involvement in the grade 3 mobility teeth when compared with grade 2 and grade 1 mobile teeth among the mandibular posteriors. However when compared with the teeth with no mobility, the grade 2 and grade 3 furcation involved teeth were more than in number in the grade 3 mobility group. The association between the degree of Mobility and severity of furcation involvement was statistically significant (Chi square test done, $p$ value $=0.018(p<0.05)$.

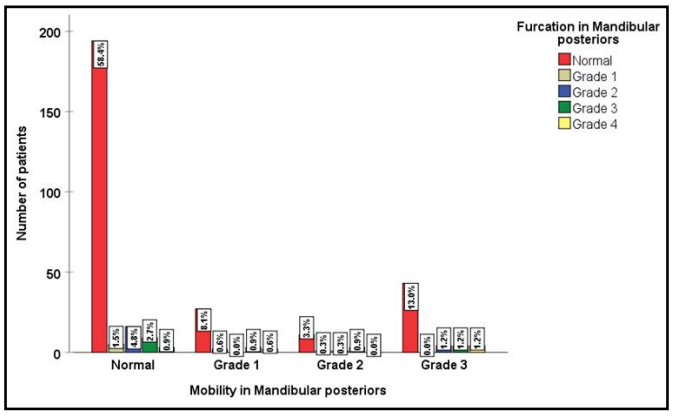

[29]. The purpose of this study is to assess the prevalence of the type of furcation defects in various grades of mobile teeth among chronic periodontitis patients.

In our study population, $60 \%$ of them were males and $40 \%$ of them were females. Mühlemann et.al stated that age was not significantly associated with the grade of tooth mobility but was significantly related to the presence of tooth mobility. Higher tooth mobility values were observed in females than in males [30]. Clement ChineduAzodo et.al concluded that one out of every ten patients attending Nigerian periodontology clinic had tooth mobility of varying grades [31]. Patrick I Ojehanonet.al from their study stated that the most mobile and earliest teeth to become mobile were the mandibular incisors, and Grade 1 severity constituted the majority [32]. Similar to the previous findings, the grade 1 mobility teeth were predominantly seen than grade 2 and grade 3 type of mobility among the posterior teeth.

The Proceedings of the World Workshop in Clinical Periodontics stated that: "Teeth with furcation invasion are at greater risk than those without such involvement, but even with furcation invasion, teeth can be successfully treated and be kept for many years if 
proper maintenance occurs" [12]. In a study done by Wang et al 1994, the influence of mobility and furcation on the molar teeth during the maintenance period of over 8 years was evaluated. The authors concluded that mobile teeth with furcation involvement were found to have more attachment loss than molars with either mobility or furcation alone [33]. Hence, tooth related factors such as mobility can adversely affect the prognosis of furcation involving teeth.

In a retrospective study done by Mc Fall, $57 \%$ of teeth which had a furcation involvement had been lost over a period of 15 years. [12]. Tooth related factors such as bifurcation ridges, root concavities, enamel pearls and narrow furcation entrances can affect the survival of the furcation involved teeth [34]. Tooth mobility is a significant risk factor for future attachment loss. Many longitudinal studies had stated that teeth with both mobility and furcation are more difficult to be maintained during the maintenance period $[12,35,36]$.

According to our present study, there was a statistically significant association seen between the degree of Mobility and furcation involvement among the posterior teeth. When interpreting this observation, it should be taken into consideration that tooth mobility of a multi-rooted tooth is usually recorded only when pronounced loss of periodontal support has taken place and therefore furcation involvement also most likely is present. However this finding cannot be generalised, since differences in periodontal disease severity exists among the study population.

In a regression model analysis study done by Cortellini et al, the greater the degree of tooth mobility, lesser is the clinical attachment level gain post operatively [37]. When deciding the treatment modalities for the furcation involved tooth, the degree of furcation involvement has routinely been the primary criteria for selecting specific treatment procedures [38]. Multiple regression analysis done by Svärdström et al, concluded that the factors which were found to significantly influence the decision of tooth extraction in molars were tooth mobility, tooth position, lack of occlusal antagonism, degree of furcation involvement, and remaining bone support [39].

The inherent subjective variation in recording Miller's index is a limitation of the present study. Hence the use of more reliable methodologies like periodontometer will allow us to better discern the effect of different degrees of tooth mobility. Potential differences in assessments of degree of furcation involvement can also be a drawback of this current retrospective analysis. Additionally future long term clinical studies should be performed to conclude if tooth mobility can be co-variable significantly associated with furcation. There is also a need for prospective, well controlled,randomized clinical trials to evaluate the influence of tooth mobility on furcation defects.

\section{Conclusion}

Within the limitations of the present retrospective analysis, a significant association exists between degree of tooth mobility and the severity of furcation involvement. Thus tooth mobility may accelerate the progression of periodontal disease in teeth with furcation involvement sites where plaque control is compromised.

\section{Acknowledgement}

The authors are thankful to Saveetha Dental College for providing a platform to express our knowledge.

\section{References}

[1]. Khalid W, Varghese SS, Sankari M, Jayakumar ND. Comparison of Serum Levels of Endothelin-1 in Chronic Periodontitis Patients Before and After Treatment. J ClinDiagn Res. 2017 Apr;11(4):ZC78-ZC81.Pubmed PMID: 28571268.

[2]. Khalid W, Vargheese SS, Lakshmanan R, Sankari M, Jayakumar ND. Role of endothelin-1 in periodontal diseases: A structured review. Indian J Dent Res. 2016 May-Jun;27(3):323-33.Pubmed PMID: 27411664.

[3]. Ramfjord SP, Caffesse RG, Morrison EC, Hill RW, Kerry GJ, Appleberry EA, et al. 4 modalities of periodontal treatment compared over 5 years. J ClinPeriodontol. 1987 Sep;14(8):445-52.Pubmed PMID: 3308969.

[4]. Pendrys DG, Katz RV. Risk of enamel fluorosis associated with fluoride supplementation, infant formula, and fluoride dentifrice use. Am J Epidemiol. 1989 Dec;130(6):1199-208.Pubmed PMID: 2589311.

[5]. Matthews DC, Smith CG, Hanscom SL. Tooth loss in periodontal patients. J Can Dent Assoc. 2001 Apr;67(4):207-10.

[6]. Carranza FA. Periodontal response to external forces. J. Clin. Periodontol. 2011:151-9.

[7]. Rohner F, Cimasoni G, Vuagnat P. Longitudinal radiographical study on the rate of alveolar bone loss in patients of a dental school. J ClinPeriodontol. 1983 Nov;10(6):643-51.Pubmed PMID: 6581178.

[8]. Hirschfeld L, Wasserman B. A long-term survey of tooth loss in 600 treated periodontal patients. J Periodontol. 1978 May;49(5):225-37.Pubmed PMID: 277674

[9]. Goldman MJ, Ross IF, Goteiner D. Effect of periodontal therapy on patients maintained for 15 years or longer: a retrospective study. J Periodontol. 1986 Jun;57(6):347-53.

[10]. Bower RC. Furcation morphology relative to periodontal treatment: Furcation entrance architecture. J Periodontol. 1979; 50: 23-27.

[11]. Loos B, Nylund K, Claffey N, Egelberg J. Clinical effects of root debridement in molar and non-molar teeth. A 2-year follow-up. J ClinPeriodontol. 1989 Sep;16(8):498-504.Pubmed PMID: 2778083.

[12]. McFall Jr WT. Tooth loss in 100 treated patients with periodontal disease: A long-term study. J. Periodontol. 1982 Sep;53(9):539-49.

[13]. Ross IF, Thompson RH Jr. A long term study of root retention in the treatment of maxillary molars with furcation involvement. J Periodontol. 1978 May;49(5):238-44.Pubmed PMID: 277675.

[14]. Wang HL, Burgett FG, Shyr Y, Ramfjord S. The influence of molar furcation involvement and mobility on future clinical periodontal attachment loss. J Periodontol. 1994 Jan;65(1):25-9.Pubmed PMID: 8133412.

[15]. Nunn ME, Fan J, Su X, Levine RA, Lee HJ, McGuire MK. Development of prognostic indicators using classification and regression trees for survival. Periodontol 2000. 2012 Feb;58(1):134-42.Pubmed PMID: 22133372.

[16]. Ravi S, Malaiappan S, Varghese S, Jayakumar ND, Prakasam G. Additive Effect of Plasma Rich in Growth Factors With Guided Tissue Regeneration in Treatment of Intrabony Defects in Patients With Chronic Periodontitis: A Split-Mouth Randomized Controlled Clinical Trial. J Periodontol. 2017 Sep;88(9):839-845.Pubmed PMID: 28474968.

[17]. Ramesh A, Vellayappan R, Ravi S, Gurumoorthy K. Esthetic lip repositioning: A cosmetic approach for correction of gummy smile - A case series. J Indian SocPeriodontol. 2019 May-Jun;23(3):290-294.Pubmed PMID: 31143013.

[18]. Ramesh A, Ravi S, Kaarthikeyan G. Comprehensive rehabilitation using dental implants in generalized aggressive periodontitis. J Indian SocPeriodontol. 2017 Mar-Apr;21(2):160-163.Pubmed PMID: 29398863.

[19]. Thamaraiselvan M, Elavarasu S, Thangakumaran S, Gadagi JS, Arthie T. Comparative clinical evaluation of coronally advanced flap with or without platelet rich fibrin membrane in the treatment of isolated gingival recession. J Indian SocPeriodontol. 2015 Jan;19(1):66.

[20]. Priyanka S, Kaarthikeyan G, Nadathur JD, Mohanraj A, Kavarthapu A. Detection of cytomegalovirus, Epstein-Barr virus, and Torque Teno virus in subgingival and atheromatous plaques of cardiac patients with chronic periodontitis. J Indian SocPeriodontol. 2017 Nov-Dec;21(6):456-460.Pubmed PMID: 29551863.

[21]. Ramesh A, Varghese SS, Doraiswamy JN, Malaiappan S. Herbs as an antioxidant arsenal for periodontal diseases. J IntercultEthnopharmacol. 2016 Jan 27;5(1):92-6.Pubmed PMID: 27069730.

[22]. Avinash K, Malaippan S, Dooraiswamy JN. Methods of Isolation and Characterization of Stem Cells from Different Regions of Oral Cavity Using 
Markers: A Systematic Review. Int J Stem Cells. 2017 May 30;10(1):12-20. Pubmed PMID: 28531913.

[23]. Kavarthapu A, Thamaraiselvan M. Assessing the variation in course and position of inferior alveolar nerve among south Indian population: A cone beam computed tomographic study. Indian J Dent Res. 2018 JulAug;29(4):405-409.Pubmed PMID: 30127186.

[24]. Mootha A, Malaiappan S, Jayakumar ND, Varghese SS, Toby Thomas J. The Effect of Periodontitis on Expression of Interleukin-21: A Systematic Review. Int J Inflam. 2016;2016:3507503.Pubmed PMID: 26998377.

[25]. Ramesh A, Varghese SS, Jayakumar ND, Malaiappan S. Chronic obstructive pulmonary disease and periodontitis-unwinding their linking mechanisms. J. Oral Biosci. 2016 Feb 1;58(1):23-6.

[26]. Varghese SS, Thomas H, Jayakumar ND, Sankari M, Lakshmanan R. Estimation of salivary tumor necrosis factor-alpha in chronic and aggressive periodontitis patients. ContempClin Dent. 2015 Sep;6(Suppl 1):S152-6. Pubmed PMID: 26604566.

[27]. Panda S, Jayakumar ND, Sankari M, Varghese SS, Kumar DS. Platelet rich fibrin and xenograft in treatment of intrabony defect. ContempClin Dent. 2014 Oct;5(4):550-4.Pubmed PMID: 25395778.

[28]. RAMAMURTHY J. COMPARISON OF EFFECT OF HIORA MOUTHWASH VERSUS CHLORHEXIDINE MOUTHWASH IN GINGIVITIS PATIENTS: A CLINICAL TRIAL. Asian J Pharm Clin Res. 2018;11(7):848.

[29]. Glargia M, Lindhe J. Tooth mobility and periodontal disease. J. Clin. Periodontol. 1997 Nov;24(11):785-95.

[30]. Mühlemann HR. Pathological tooth mobility. Annu Meet Am Inst Oral Biol 1969; 99-101.
[31]. Oginni FO. Tooth loss in a sub-urban Nigerian population: causes and pattern of mortality revisited. Int Dent J. 2005 Feb;55(1):1.Pubmed PMID: 15747648.

[32]. Ojehanon P, Azodo C, Erhabor P. Periodontal characteristics of diabetic patients with tooth mobility. Journal of Social Health and Diabetes 2017; 05: 094-099.

[33]. Wang HL, Burgett FG, Shyr Y, Ramfjord S. The influence of molar furcation involvement and mobility on future clinical periodontal attachment loss. J Periodontol. 1994 Jan;65(1):25-9.Pubmed PMID: 8133412.

[34]. Bower RC. Furcation morphology relative to periodontal treatment: Furcation root surface anatomy. J Periodontol. 1979; 50: 366-374.

[35]. Knowles J, Burgett F, Morrison E, Nissle R, Ramfford S. Comparison of results following three modalities of periodontal therapy related to tooth type and initial pocket depth. J ClinPeriodontol. 1980 Feb;7(1):32-47.Pubmed PMID: 6988468.

[36]. Becker W, Becker BE, Berg LE. Periodontal treatment without maintenance: a retrospective study in 44 patients. J. Periodontol.. 1984 Sep;55(9):505-9.

[37]. Cortellini P, Tonetti MS, Lang NP, Suvan JE, Zucchelli G, Vangsted T, et al. The simplified papilla preservation flap in the regenerative treatment of deep intrabony defects: clinical outcomes and postoperative morbidity. J Periodontol. 2001 Dec;72(12):1702-12.Pubmed PMID: 11811506.

[38]. Hamp SE, Nyman S, Lindhe J. Periodontal treatment of multi rooted teeth. Results after 5 years. J. Clin. Periodontol. 1975 Sep;2(3):126-35.

[39]. Svärdström G, Wennström JL. Periodontal treatment decisions for molars: an analysis of influencing factors and long-term outcome. J Periodontol. 2000 Apr;71(4):579-85.Pubmed PMID: 10807122. 